\title{
UTAUT Model: Identifying The Driving Factors of The Intention to Use Paylater
}

Submitted Date :

30 August 2021

Accepted Date :

21 September 2021

\author{
Yeyen Pratika* \\ Management Department \\ Universitas Muhammadiyah Malang, Indonesia \\ yeyenpratika@umm.ac.id
}

Suggested Citation:

Al-Saedi, K., Al-Emran, M., Ramayah, T., \& Abusham, E. (2020). Developing a general extended UTAUT model for M-payment adoption. Technology in Society, 62 (September 2019), 101293. https://doi.org/10.1016/i.techsoc.2020.101293

Abstract:

Information and Communication Technology (ICT) has developed rapidly that drives to the growth of digital transaction in recent years. E-commerce companies create features in order to deal with their customers, such as paylater in their digital payment. It offers a payment method that is almost similar to a credit card which allows customers to buy products or services right now with the delaying of payment. This phenomenon becomes regular in e-commerce business. Thus, this study aims to examine what factors influence individual behavioral intention in adopting paylater by using Unified Theory of Acceptance and Use of Technology (UTAUT) theory. A total of 167 respondents was involved in this study. Data were analyzed by using Structural Equation Modeling (SEM). The result showed that only performance expectancy and facilitating conditions have a significant influence on behavioral intention.

Keywords Digital Payment; Intention Behavior; Paylater; UTAUT

JEL Classification: M31

${ }^{*}$ Corresponding Author 


\section{Research Background}

Online shopping has become an integral part of Indonesian consumers. The report provided by JP Morgan mentioned that Indonesia's business to consumer e-commerce market is worth $\$ 13.6$ billion and predicted to increase about 34.6 percent in 2021. This number shows that the development of online shopping will keep growing in the following years. The growth is certainly supported by adequate infrastructure, such as internet connection speeds and digital payment system. Although the internet connection speeds in Indonesia is far below the average of worldwide speeds, the number of internet users in Indonesia has reached 175.4 million people with the total population of Indonesia is around 272.1 million people (JPMorgan, 2019). The same report also mentioned that Indonesia is in third place with a population growth rate of accessing the internet by 17 percent or 25.3 million users in 2019.

As internet user and online shopping keep growing, payment system alternatives also increase. The report of Indonesia e-commerce payment trends shows that when shopping online, cards are Indonesia's dominant payment form, taking a 34 percent of the market (JPMorgan, 2019). However, financial technology also known as fintech has grown in major ways and is continually maturing in Indonesia. Fintech has various services that makes consumers easy to access financial things compared to the traditional, such as transaction payment, investment, capital raising, fundraising, insurance, etc. According to the OJK (Otoritas Jasa Keuangan), there are 100 licensed fintech lending companies in the early 2020 and expected to rise throughout the year.

One interesting of fintech development is the paylater system that functions like a credit card. It facilitates consumers to get credit with a certain limit. Based on a research conducted by DSResearch (2019), it addressed that paylater is the third most popular fintech product in Indonesia. The evolution of mobile commerce has three intersecting dimensions, namely mobile payment, mobile marketing and mobile banking that create the existence of a loan system for mobile transcation (McKinsey, 2011) Those dimensions are interpreted by companies as new opportunity. Thus, many companies engaged in online shopping take this opportunity by providing paylater features in their services, such as OVO, GOJEK, Shopee, Traveloka, etc.

Moreover, the existence of this paylater feature encourages the emergence of paylater adoption phenomenon in Indonesian market. Basically, various research models have been developed to explain the factors that influence the intention and interest of using techonology. One of the well-known theories is Unified Theory of Acceptance and Use of Technology (UTAUT) model, developed by Venkatesh, Morris, Davis, \& Davis in 2003. This theory consists of four variables which are performance expectancy, effort expectancy, social influence and facilitating condition. Many studies have been carried out by using this model with different objects, such as mobile banking (Alalwan et al., 2017), mobile payment (Oliveira et al., 2016), mobile health (Duarte \& Pinho, 2019), bicycle sharing system (Jahanshahi et al., 2020), etc. Those studies found that the variables provide the intention of individual to use the technology.

Previous study conducted in mobile banking shows several factors that indicate individual's intention to use mobile banking. Combined with trust, this research found that performance expectancy, trust, and effort expectancy influence behavioural intention of consumers in using mobile banking (Alalwan et al., 2017). In mobile payment, a study that combines conceptual model related to UTAUT, Diffusion of Innovation (DOI) and security perception underlined that only performance expectancy and social factor influence the behavioural intention, however effort expectancy and facilitating condition have no stimulus on the intention of consumers (Oliveira et al., 2016). Although the research related to technology adoption using UTAUT model have been widely used, but it is still limited study that conduct on paylater system. Thus, this study aims to examine the factors influence consumers' behavioural intention in adopting paylater system.

Unified Theory of Acceptance and Use of Technology (UTAUT) is a theoretical model that integrates eight theories of technology acceptance which are Theory of Reasoned Action (TRA), Technology Acceptance Model (TAM), Motivational Model (MM), Theory of Planned Behavior (TPB), A Model Combining the Technology Acceptance Model and the Theory of Planned Behavior (C-TAM-TPB), The Model of PC Utilization (MPCU), the Innovation Diffusion Theory (IDT), dan the Social Cognitive Theory (SCT). This theory is developed by Venkatesh et al. (2003). Originally, UTAUT model has four important dimensions (performance expectancy, effort expectancy, social influence and facilitating condition), but this theory develops with three other dimensions (hedonic motivation, price value and habit) that known as UTAUT2 (Venkatesh, Thong, \& Xu, 2016). However, in this research only focus on UTAUT considering paylater is relatively new.

Performance expectancy is the extent to which the use of technology will provide benefits to consumers in carrying out certain activities (Venkatesh et al., 2003). Several previous studies stated that individual is motivated to use and accept a new technology if he has a perception that this technology will be useful for his daily life (Al- 
Saedi, Al-Emran, Ramayah, \& Abusham, 2020; Alalwan et al., 2017). In research related to mobile health, it is stated that several aspects needed to measure the adoption factors, such as performance expectancy (Duarte \& Pinho, 2019). Furthermore, in the qualitative research also mentioned that performance expectation has an influence in adoption mobile banking services (Gharaibeh, Arshad, \& Gharaibh, 2018). In addition, the previous study also underlined that performance expectancy is the most influence factor in the intention of older adults to use technology (Macedo, 2017).

Effort expectancy is the level of ease associated with the use of technology (Venkatesh et al., 2003). Consumer will show more of their intention to use digital money if it looks easy to use (Megadewandanu, Suyoto, \& Pranowo, 2017). Effort expectancy is the factor that affects individual's behavioral intention in adopting technology, especially mobile banking (Alalwan et al., 2017). Consumers tend to pay attention to the ease or difficulty of using mobile banking, so that they need sufficient knowledge and expertise to be able to use this technology without any assistance from other people. Consumer who have used internet banking say that mobile application is easy to use because they already have certain experience and are encouraged to use mobile banking (Gharaibeh et al., 2018). For older adults, effort expectancy is an important factor that affect them to adopt a new technology (Macedo, 2017).

Social influence is the degree to which an individual perceives that other people, who are considered important (eg. family and friends), believe that they must use certain technologies (Venkatesh et al., 2003). As an individual in society, consumer is very susceptible to friends or colleagues, particularly those who have a major impact on him (Cao \& Niu, 2019). Their opinion affects how he views a new technology. In addition, an individual has a tendency to obtain information about a product by asking other people who use the same product (Macedo, 2017). Previous studies also claimed that social factors have an influence on individual intention to use technology such as mobile banking (Gharaibeh et al., 2018), mobile payment (Slade, Dwivedi, Piercy, \& Williams, 2015) and online games (Ramírez-Correa, Rondán-Cataluña, Arenas-Gaitán, \& Martín-Velicia, 2019). Social factors also affect older adults in adopting new technology (Macedo, 2017), so that a word-of-mouth approach is needed when targeting this segment (Oh \& Yoon, 2014).

Facilitating condition refers to the extent an individual believes that technical or organizational infrastructure support the usage of technology and system (Venkatesh et al., 2003). There are several researches that discuss the differences between technology adoption in developed and developing countries considering the different conditions and factors behind it (Megadewandanu et al., 2017). Internet speed in a country will certainly be an important indicator of whether or not its citizens will adopt technology offered. Facilitating conditions are a very important role in adopting technology because individuals need to be facilitated with the right smartphone, adequate knowledge and services regarding the technology to be used (Gharaibeh et al., 2018). Several studies agreed that facilitating conditions have a significant influence on individual intention to use technology (Duarte \& Pinho, 2019; Gharaibeh et al., 2018; Macedo, 2017).

\section{Research Method}

A quantitative approach is used in this study with the users of e-commerce applications that provide paylater system as the population. Purposive sampling is applied in this research with the criteria users who ever used paylater system at least once. Structural Equation Modelling (SEM) is used in this study by using Partial Least Square. SEM is multivariate analysis technique that combines factor analysis and multiple regression, allowing researchers to test the relationship between independent and dependent variables simultaneously (Hair, Black, Babin, \& Anderson, 2014). This study uses outer model to check the validity and reliability that is indicated through the value of Average of Variance Extracted (AVE), Confirmatory Factor Analysis (CFA) and Construct Reliability (CR). The value of CFA and CR are considered as good if it is $\geq 0.7$ and AVE should be $\geq 0.7$ (Hair, Black, Babin, \& Anderson, 2014). Moreover, this study also uses inner model to predict the causal relationship between latent variables. The inner model is evaluated by comparing the values of construct R-square and measuring the value of $Q$-square. A total of 18 indicator statements are used in this study to examine the proposed research model as mentioned on Table 1 below. 
Table 1. Indicator Statement

\begin{tabular}{lll}
\hline \multicolumn{1}{c}{ Construct } & Code & \\
\hline Performace & PE1 & I find paylater useful in my daily life \\
Expectancy & PE2 & Using paylater increases my chances of achieving tasks that are important to me \\
& PE3 & Using paylater helps me accomplish tasks more quickly \\
Effort Expectancy & EE4 & Using paylater increases my productivity \\
& EF2 & Learning how to use paylater is easy for me \\
& EF3 & I find paylater easy to use \\
Social Influence & EF4 & It is easy for me to become skillful at using paylater \\
& SI1 & People who are important to me think that I should use paylater \\
& SI2 & People who influence my behaviour think that I should use paylater \\
Facilitating & SI3 & People whose opinions that I value prefer that I use paylater \\
Conditions & FC1 & I have the knowledge necessary to use paylater \\
& FC2 & Paylater is compatible with other technologies I use \\
Behavioral Intention & FC3 & I can get help from others when I have difficulties using paylater \\
& BI1 & I intend to use paylater in the future \\
& BI2 & I will always try to use paylater in my daily life \\
& BI3 & I plan to use paylater in the future \\
BI4 & I predict I would use paylater in the future \\
\hline
\end{tabular}

Source: (Venkatesh et al., 2003)

Result

This study involved 167 respondents in Indonesia. The characteristics respondent based on demographic approach can be summarized in Table 2 below.

Table 2. Demographic Characteristics

\begin{tabular}{|c|c|c|c|}
\hline Category & Explanation & Frequency & Percentage \\
\hline \multirow[t]{2}{*}{ Gender } & Male & 58 & $34.73 \%$ \\
\hline & Female & 109 & $65.27 \%$ \\
\hline \multirow[t]{5}{*}{ Age Range } & $17-21$ & 25 & $14.97 \%$ \\
\hline & $22-26$ & 28 & $16.77 \%$ \\
\hline & $27-31$ & 85 & $50.90 \%$ \\
\hline & $32-36$ & 21 & $12.57 \%$ \\
\hline & $37-41$ & 8 & $4.79 \%$ \\
\hline \multirow[t]{3}{*}{ Latest Education } & High School & 40 & $23.95 \%$ \\
\hline & Undergraduate Degree & 63 & $37.72 \%$ \\
\hline & Master/Doctoral Degree & 64 & $38.32 \%$ \\
\hline \multirow[t]{6}{*}{ Occupation } & Student & 48 & $28.74 \%$ \\
\hline & Employee & 56 & $33.53 \%$ \\
\hline & Professional (doctor, lawyer, etc) & 33 & $19.76 \%$ \\
\hline & Entrepreneur & 18 & $10.78 \%$ \\
\hline & Housewife & 11 & $6.59 \%$ \\
\hline & Others & 1 & $0.60 \%$ \\
\hline \multirow[t]{6}{*}{ Monthly Income } & Less than IDR 2,000,000 & 40 & $23.95 \%$ \\
\hline & IDR 2,000,000 - 2,999,999 & 21 & $12.57 \%$ \\
\hline & IDR 3,000,000 - 3,999,999 & 24 & $14.37 \%$ \\
\hline & IDR 4,000,000 - 4,999,999 & 18 & $10.79 \%$ \\
\hline & IDR 5,000,000 - 5,999,999 & 21 & $12.57 \%$ \\
\hline & More than IDR 5,999,999 & 43 & $25.75 \%$ \\
\hline \multirow{4}{*}{$\begin{array}{l}\text { The Most } \\
\text { Application } \\
\text { Used }\end{array}$} & Gopay & 30 & $17.96 \%$ \\
\hline & ovo & 34 & $20.36 \%$ \\
\hline & Shopee & 77 & $46.11 \%$ \\
\hline & Traveloka & 26 & $15.57 \%$ \\
\hline
\end{tabular}

Source: Data Processed (2021) 
From the data above, it can be concluded that the majority of respondent are women (65.27\%). Most of them are in the age range of $27-31$ years $(50,90 \%)$. Basically, the respondent is dominated by workers with a total of 107 respondents $(64.07 \%)$. It also showed that most respondent has an average monthly income more than IDR 5,999,999 (25.75\%). In addition, 77 respondents (46.11\%) mentioned that the most attractive paylater feature is Shopee.

According to the table above, this study has the convergent validity and reliability that meets the requirement because all the value of standardized factor loading, AVE and CR are more than 0.50 . In addition, the discriminant validity by using Fornell-Larcker can be provided in Table 4 . Discriminant validity aims to measure the indicators with latent variables by comparing the value of cross loading factor. discriminant validity in this study also meets the criteria.

The result of this study also show that R2 value for behavioural intention is 0.537 which means performance expectancy, effort expectancy, social influence and facilitating condition are able to explain behavioural intention variable in this study with a percentage of $53.70 \%$ and the remaining of $46.30 \%$ is explained by other variables outside this research model. Additionally, $\mathrm{Q}^{2}$ with the same percentage of $53.70 \%$ illustrates the data diverse of this structural model.

Table 3. Output of Measurement

\begin{tabular}{lllcc}
\multicolumn{1}{c}{ Construct } & Item & SFL & AVE & CR \\
\hline Performance & PE1 & 0.914 & 0.730 & 0.915 \\
Expectancy & PE2 & 0.871 & & \\
& PE3 & 0.868 & & \\
& PE4 & 0.757 & & \\
Effort & EE1 & 0.833 & 0.783 & 0.935 \\
Expectancy & EE2 & 0.924 & & \\
& EE3 & 0.889 & & \\
Social & EE4 & 0.891 & & \\
Influence & SI1 & 0.929 & 0.875 & 0.955 \\
& SI2 & 0.933 & & \\
Facilitating & S13 & 0.945 & & \\
Condition & FC1 & 0.901 & 0.685 & 0.866 \\
& FC2 & 0.880 & & \\
Behavioral & FC3 & 0.684 & & \\
Intention & BI1 & 0.930 & 0.771 & 0.930 \\
& BI2 & 0.943 & & \\
& B13 & 0.882 & & \\
\hline
\end{tabular}

Source: Data Processed (2021)

Table 4. Output of Discriminant Validity

\begin{tabular}{llllll} 
& BI & EE & FC & PE & SI \\
BI & 0.878 & & & & \\
EE & 0.589 & 0.885 & & & \\
FC & 0.594 & 0.628 & 0.828 & & \\
PE & 0.676 & 0.684 & 0.597 & 0.854 & \\
SI & 0.529 & 0.434 & 0.573 & 0.533 & 0.936 \\
\hline
\end{tabular}

Source: Data Processed (2021)

The result of this study can be concluded as mentioned on Table 5 and Figure 1 below. From the result, it can be summarized that there are only 2 supported hypotheses and the other 2 hypotheses are not supported. 
Table 5. Output of Hypothesis Testing

\begin{tabular}{lrrrl}
\multicolumn{1}{c}{ Hypothesis } & Effect & \multicolumn{1}{c}{ t-value } & t-table & \\
$\mathrm{H} 1: \mathrm{PE} \rightarrow \mathrm{Bl}$ & 0.386 & 3.690 & & Yes \\
$\mathrm{H} 2: \mathrm{EE} \rightarrow \mathrm{Bl}$ & 0.140 & 1.735 & 1,96 & No \\
$\mathrm{H} 3: \mathrm{SI} \rightarrow \mathrm{Bl}$ & 0.155 & 1.681 & & No \\
$\mathrm{H} 4: \mathrm{FC} \rightarrow \mathrm{Bl}$ & 0.187 & 1.977 & & Yes \\
\hline
\end{tabular}

Source: Data Processed (2021)

\section{Discussion}

\section{Performance Expectancy Affects Behavioral Intention}

The first result of this hypothesis where performance expectancy influence behavioral intention is supported by several previous researches. Performance expectancy show a significant effect on individual's interest in using technology (Venkatesh et al., 2003, 2016). The development of technology that offers benefits encourage consumers to use it. In this study, consumers found that paylater can provide them with many opportunities. Thus, consumers intend to try and use paylater system provided by e-commerce. This result is also in line with previous study that mentioned performance expectancy drives individual's intention to use transportation system (Alshehri, Drew, \& AlGhamdi, 2012). Consumers only need to tap their e-money on machine and it can record their payment easier. In addition, the same result also occurred on factors influence consumers' behavioral intention in using mobile application (Gupta, Dogra, \& George, 2018) and mobile payment (Oliveira et al., 2016).

\section{Effort Expectancy Affects Behavioral Intention}

Morever, the other result in this study say that effort expectancy does not have a significant influence on behavioral intention. It certainly contradicts with several researches that address effort expectancy effects individual's behavioral intention (Al-Saedi et al., 2020; Venkatesh et al., 2003, 2016; Ye, Zheng, \& Yi, 2020) (AlSaedi et al., 2020). This study does not reflect the same result in Indonesia. However, previous research conducted in mobile payment has the same result with this current study that claimed effort expectancy has no effect on behavioural intention (Oliveira et al., 2016). As known that paylater is easy to use and has no need many efforts to apply, it makes no effect on consumers. Currently, the level of consumer familiarity towards technology is also increasing, so that adopting a new technology does not give them any difficulties. In addition, most of respondents in this study were dominated by millennial who really immerse on technology.

\section{Social Influence Affects Behavioral Intention}

This study also found that there is no effect between social influence and behavioural intention. It has different result to previous researches conducted in applying new technology (Oliveira et al., 2016; Venkatesh, Thong, \& $\mathrm{Xu}, 2012$; Venkatesh et al., 2016). It is caused by the function of paylater system. Consumers view paylater as a system that provides benefit for them. Consumers do not need to be influenced by others in adopting this new payment system. However, this result is in line with research conducted on the use of mobile banking (Pertiwi \& Ariyanto, 2017) (Pertiwi \& Ariyanto, 2017) and government electronic service (Alshehri et al., 2012).

\section{Facilitating Condition Affects Behavioral Intention}

The last result indicates that facilitating condition has a significant influence on behavioural intention in using paylater system. It is supported by several previous researches (Duarte \& Pinho, 2019; Gharaibeh et al., 2018; Macedo, 2017). It illustrates that the circumstances around consumer related to knowledge, devices and place to ask encourage consumers to use a technology. When planning to use paylater feature, consumers can identify that their current device can support it. They also already have certain knowledge regarding technology, so it becomes easy to them in adopting or applying paylater system. Thus, facilitating condition is very important role in supporting behavioural intention of individual, especially in using a new technology.

The development of technology continues to grow significantly which encourages high competition and ongoing changes in technology use. Thus, companies should consider technology as a part of their business process. It aims to drive consumers in purchasing their product by using the current technology. Companies have expectation that by providing paylater system it can increase their sales volume. Consumers who do not have enough money can still buy their products by delaying the payment.

However, because of the new payment system, consumers are still reluctant to use this system. Thus, companies need to pay attention to what factors encourage consumers to adopt this technology. Companies can 
implement their marketing strategies by adjusting consumer behaviour such as giving discount or cashback if consumers use paylater. Meanwhile, government as policy maker needs to provide security guarantees for consumers regarding paylater system considering this system is also provided by non-banking companies. It is intended to guarantee consumers' interest and also to prevent problems in the future.

Paylater system is the result of technology development that generate certain responses for consumers. These responses formed factors that influence individual in adopting new technology. As a new transformation in digital payment technology, paylater feature creates consumer behaviour in market. The result of this study underlined that performance expectancy and facilitating condition effect the behavioural intention of individual to use paylater system. Although paylater is relatively new in Indonesia, consumers believe that paylater can provide them with benefits in order to achieve their goals. It is caused by the easy process of purchase payment through this system.

\section{Conclusion}

Generally, it can be concluded that several factors influence consumers in adopting a technology. It also applies to the current technology that makes consumers easy to buy and pay for product. Paylater system lets consumers to purchase a product or service right away and pay it later. This results of this study indicate that performance expectancy and facilitating condition influence consumer's behavioral intention in using or adopting technology. However, effort expectancy and social influence have no significant influence on it. The results of this study provide suggestions for companies to improve the performance and facilities so that consumers are increasingly encouraged to use this paylater system. Speeding up the registration and payment process can be the best alternative to boost the usage. In addition, companies can continue to update these payment features according to developing trends and technologies.

Although this study can contribute to the marketing literature and consumer behavior, especially that involving technology, this research still has some limitations. The data collected through online system can cause the uncertainty condition of respondents when filling out the questionnaire. The distribution of data is limited to several cities in Indonesia, so it cannot describe Indonesian consumers as a whole. The result figured out that the research model is moderate that needs other variables to be fitted. So, the next research is suggested to use the advanced theory of UTAUT, which is known as UTAUT2. It adds other variables such as hedonic motivation, price value and habit.

\section{References}

Al-Saedi, K., Al-Emran, M., Ramayah, T., \& Abusham, E. (2020). Developing a general extended UTAUT model for M-payment adoption. Technology in Society, 62(September 2019), 101293. https://doi.org/10.1016/j.techsoc.2020.101293

Alalwan, A. A., Dwivedi, Y. K., \& Rana, N. P. (2017). Factors influencing adoption of mobile banking by Jordanian bank customers: Extending UTAUT2 with trust. International Journal of Information Management, 37(3), 99-110. https://doi.org/10.1016/j.ijinfomgt.2017.01.002

Alshehri, M., Drew, S., \& AlGhamdi, R. (2012). Analysis of citizens' acceptance for e-government services: Applying the utaut model. Proceedings of the IADIS International Conference, ISPCM 2012, Proceedings of the IADIS International Conference TPMC 2012, IADIS International Conference IAR 2012, 69-76.

Cao, Q., \& Niu, X. (2019). Integrating context-awareness and UTAUT to explain Alipay user adoption. International Journal of Industrial Ergonomics, 69(March 2018), 9-13. https://doi.org/10.1016/j.ergon.2018.09.004

Duarte, P., \& Pinho, J. C. (2019). A mixed methods UTAUT2-based approach to assess mobile health adoption. Journal of Business Research, 102(February), 140-150. https://doi.org/10.1016/j.jbusres.2019.05.022

Gharaibeh, M. K., Arshad, M. R. M., \& Gharaibh, N. K. (2018). Using the UTAUT2 model to determine factors affecting adoption of mobile banking services: A qualitative approach. International Journal of Interactive Mobile Technologies, 12(4), 123-134. https://doi.org/10.3991/ijim.v12i4.8525

Gupta, A., Dogra, N., \& George, B. (2018). What determines tourist adoption of smartphone apps? Journal of Hospitality and Tourism Technology, 9(1), 50-64. https://doi.org/10.1108/jhtt-02-2017-0013

Hair, J. F., Black, W. C., Babin, B. J., \& Anderson, R. E. (2014). Multivariate Data Analysis (7th ed.). Essex: 
Pearson Education.

Jahanshahi, D., Tabibi, Z., \& van Wee, B. (2020). Factors influencing the acceptance and use of a bicycle sharing system: Applying an extended Unified Theory of Acceptance and Use of Technology (UTAUT). Case Studies on Transport Policy, (August). https://doi.org/10.1016/j.cstp.2020.08.002

JPMorgan. (2019). E-commerce Payments Trends: Indonesia Indonesia's e-commerce market trends : Major growth boosted by economic gains. 2019 J.P. Morgan Global Payment Trends, 1-10.

Macedo, I. M. (2017). Predicting the acceptance and use of information and communication technology by older adults: An empirical examination of the revised UTAUT2. Computers in Human Behavior, 75, 935-948. https://doi.org/10.1016/j.chb.2017.06.013

McKinsey. (2011). The road to mobile payments services. Online, (June 2010), 45-52.

Megadewandanu, S., Suyoto, \& Pranowo. (2017). Exploring mobile wallet adoption in Indonesia using UTAUT2: An approach from consumer perspective. Proceedings - 2016 2nd International Conference on Science and Technology-Computer, ICST 2016, (May 2019), 11-16. https://doi.org/10.1109/ICSTC.2016.7877340

Oh, J. C., \& Yoon, S. J. (2014). Predicting the use of online information services based on a modified UTAUT model. Behaviour and Information Technology, 33(7), 716-729. https://doi.org/10.1080/0144929X.2013.872187

Oliveira, T., Thomas, M., Baptista, G., \& Campos, F. (2016). Mobile payment: Understanding the determinants of customer adoption and intention to recommend the technology. Computers in Human Behavior, 61(2016), 404-414. https://doi.org/10.1016/j.chb.2016.03.030

Pertiwi, ni wayan dewi mas yogi, \& Ariyanto, D. (2017). Penerapan Model Utautt. 18, 1369-1397.

Ramírez-Correa, P., Rondán-Cataluña, F. J., Arenas-Gaitán, J., \& Martín-Velicia, F. (2019). Analysing the acceptation of online games in mobile devices: An application of UTAUT2. Journal of Retailing and Consumer Services, 50(April), 85-93. https://doi.org/10.1016/j.jretconser.2019.04.018

Slade, E. L., Dwivedi, Y. K., Piercy, N. C., \& Williams, M. D. (2015). Modeling Consumers' Adoption Intentions of Remote Mobile Payments in the United Kingdom: Extending UTAUT with Innovativeness, Risk, and. Psychology \& Marketing, 32(8), 860-873. https://doi.org/10.1002/mar.20823

Venkatesh, V., Morris, M. G., Davis, G. B., \& Davis, F. D. (2003). User Acceptance of Information Technology: Toward a Unified View. MIS Quarterly, 27(3), 425. https://doi.org/10.2307/30036540

Venkatesh, V., Thong, J. Y. L., \& Xu, X. (2012). Consumer Acceptance and Use of Information technology: Extending the Unified Theory of Acceptance and Use of technology. MIS Quarter, 36(1), 157-178.

Venkatesh, V., Thong, J. Y. L., \& Xu, X. (2016). Unified theory of acceptance and use of technology: A synthesis and the road ahead. Journal of the Association of Information Systems, 17(5), 328-376.

Ye, J., Zheng, J., \& Yi, F. (2020). A study on users' willingness to accept mobility as a service based on UTAUT model. Technological Forecasting and Social Change, 157(April), 120066. https://doi.org/10.1016/j.techfore.2020.120066 